\title{
Comparative Staging of Blastoderm Development at Oviposition in Eggs from Layer and Broiler Grandparent Breeder Flocks
}

\author{
Serdar Özlü ${ }^{1, a, *}$ \\ ${ }^{1}$ Department of Animal Science, Faculty of Agiculture, Ankara University, 06110 Ankara, Turkey \\ *Corresponding author
}

A R T I C L I N F O A B S T R A C T

Research Article

Recent decades were characterized by genetic selection of broiler and layer chickens for enhanced growth rate and meat yield or intensified egg production, respectively. It is to be expected that genetic selection for various traits would also influence embryo development. The effects of different strains of chickens on egg weight, stage of blastoderm, variation of the blastoderm

Received : 29/03/2021

Accepted : 05/07/2021 development and Pearson correlation between egg weight and stage of blastoderm at oviposition were studied in the current study. Hatching eggs were randomly collected from three layer chicken lines (Layer-1, Layer-2, and Layer-3) raised in Poultry Research Institute, and two broiler grandparent flocks (Female and Male) from Aviagen Anadolu. The age of all chicken lines was 36 week. A total of $30 \mathrm{eggs}$ in each line were used, and egg weight and the blastoderm development of the embryos were determined at oviposition time. At the end of the research, significant

Keywords:

Egg weight

Blastoderm development

Layer breeder

Broiler grandparents

Embryo staging difference in egg weights were observed for all lines except between Layer-1 and Layer-2, between Layer-2 and Female grandparent line. The mean stage of blastoderm development in male grandparent line eggs significantly lower than other four genetic lines. Moreover, the coefficient of variance $(\mathrm{CV})$ of blastoderm developments was 4.30, 3.42, 3.60, 6.27, and 11.33 for Layer-1, Layer2, Layer-3, Female, and Male grandparent lines, respectively. However, there was no significant correlation between egg weight and stage of blastoderm development for all flocks. It can be concluded that genetic selection affects not only production traits but also developmental pattern of the embryos in the oviduct. Hence, it may be beneficial to adjust storage condition according to the line being used.

\section{Introduction}

It is well known that success in poultry production primarily depends on some factors, such as flock age, egg weight, incubation condition, feeding and management during posthatch period (Ipek and Sahan, 2002; Badowski et al., 2005; Weis et al., 2011). The progression of age differently reflects egg weight and egg composition in divergent bird species (chicken, turkey, duck, etc.), strain and yield type (meat or egg type) (Sözcü and Ipek, 2017). Egg weight is a primary factor that affects egg composition and embryo growth, and besides egg weight is positively correlated with hatchability (Ng'ambi et al., 2013). Hatching eggs can be stored below ambient temperature prior to incubation, which is a common practice in breeding farms and hatcheries. The storage period varies due to market demand for day old chicks and hatchery capacities. Generally, commercial hatcheries set their eggs after 3 to 5 $\mathrm{d}$ of storage to minimize the negative effects of prolonged storage on hatchability and chick quality. Preincubation of hatching eggs before or during storage has been reported to reduce the detrimental effects of periods of storage greater than 7 d (Fasenko et al., 2001a, b; Reijrink et al., 2009; Gucbilmez et al., 2013; Özlü et al., 2021a, b). The effect of preincubation on hatchability has been found to be influenced by the length of egg storage period and the developmental stage of the embryo before the heating treatment (Meir and Ar, 1998; Reijrink et al., 2009).

The Hamburger and Hamilton (1992; HH) procedure describing the progressive stages of embryo development during incubation is the most widely used normal table. They described chicken embryo development from the onset of primitive streak formation through hatch. However, Eyal Giladi and Kochav (1976; EGK) devised a 14-stage classification of the morphogenetic development of the early chicken embryo during the preoviposition, and oviductal period. Staging procedures similar to the EGK for the chicken have been described by Gupta and Bakst 
(1993) for the turkey, Dupuy et al. (2002) for the Pekin duck, and Łukaszewicz et al. (2017) for the goose. Moreover, in a study of Sellier et al. (2006) the developmental stages of embryos in chicken, Moscovy duck, Pekin duck, mule duck, turkey, Japanese quail, goose, and Guinea fowl eggs at 5 to $7 \mathrm{~h}$ after ovulation through $72 \mathrm{~h}$ of incubation were compared. These authors reported that chicken is further along in development, often at the onset of hypoblast formation, at the time of oviposition, whereas the turkey egg must be incubated for the onset of the hypoblast formation. On the other hand, van den Brand et al. (2019) found that there was no difference in both layer crossbreds, and Bakst et al. (2012) carried out a study to compare the blastoderm development of two broiler lines eggs under different storage periods. Broiler and layer strains had been intensively selected over many years for different production purposes, the former especially for growth rate and meat yield, and the latter mainly for total egg production. Moreover, several comparative studies between layers and broilers (Jackson and Diamond, 1996; Mahagna and Nir, 1996; Koenen et al., 2002; Everaert et al., 2008; Druyan, 2010) revealed differences between the breeds in several production traits. Sato et al. (2006) observed differences in heat production and lipid metabolism between the broiler and layer embryos. Furthermore, the yolk and total energy content of broiler eggs was higher than that of layer eggs (Nangsuay et al., 2015). All of these factors may determine the developmental differences between broiler and layer embryos (Druyan, 2010). However, the information about the initial blastoderm developments of the both strains is very little. Consequently, the objective of the present study was to compare egg weight and the stage of blastoderm development at oviposition in eggs from three layer breeders and two broiler grandparent (male and female lines) flocks.

\section{Materials and Methods}

\section{Birds and Egg Collection}

Hatching eggs were randomly collected from three layer chicken lines (Layer-1, Layer-2, and Layer-3) raised in Poultry Research Institute (Ankara, Turkey), and two broiler grandparent flocks (Female and Male) from Aviagen Anadolu (Ankara, Turkey). The age of all chicken lines was $36 \mathrm{wk}$. In both facilities, all the eggs were cleared from the cage (layer lines) or nests (broiler grandparent lines) immediately after the lights were turned on in the houses before egg collection, to ensure that the eggs laid late the previous day were not selected. The freshly collected 30 eggs in each flock were transported (approximately $2 \mathrm{~h}$ ) to the Chicken Education Unit at Ankara University (Ankara, Turkey).

\section{Embryo Collection and Staging}

Individual egg weight was measured with an electronic balance to the nearest $0.01 \mathrm{~g}$ before examination. The embryos were isolated from the yolk using the filter ring technique, as described by Gupta and Bakst (1993). The dorsal and ventral sides of the embryo identified with a stereomicroscope (Leica S6D, Leica Microsystems GmbH, Wetzlar, Germany), to determine the stage of embryonic development according to the classification table of Eyal Giladi and Kochav (1976), with a score of 7 to 11 corresponding to stages EGK-VII to EGK-XI, respectively.

\section{Statistical Analyses}

The blastoderm development of the embryos are presented as mean \pm SEM. Statistical analysis was carried out by one-way analysis of variance (ANOVA), KruskalWallis nonmarapetric test, or Z-Test (percentages of particular stages) to determine differences by the statistical package Minitab Version 14 (Minitab, Inc., State College, PA). Significant difference among the breeder line means were determined using least squares with Duncan's multiple range test. Claims of significant dfference were based upon $\mathrm{P} \leq 0.05$. The Pearson's product correlation coefficient (r) was used to determine the egg weight and stage of blastoderm development of a linear relationship.

\section{Results and Discussion}

\section{Egg weight of Five Strains}

The descriptive statistics of the egg weight has been given in Table 1. Durmuş and Türkoğlu (2007) reported that there was no significant difference in egg weight of layer type pure lines, but they found that crossbreed lines had a significant difference in egg weight. Similarly, egg weights of layer flocks were significantly different except Layer-1 and Layer-2 in the current study. Furthermore, male grandparent flock had a significantly higher egg weight than those of female grandparent flock. However, Nangsuay et al. (2015) did not find any significant difference in egg weight of broiler and layer hatching eggs.

Table 1. Descriptive statistics of the egg weight which collected from five strains.

\begin{tabular}{|c|c|c|c|c|}
\hline \multirow{2}{*}{ Strain } & \multicolumn{4}{|c|}{ Egg Weight } \\
\hline & Mean $(\mathrm{g}) \pm \mathrm{SEM}^{1}$ & Minimum (g) & Maximum (g) & $\% \mathrm{CV}^{2}$ \\
\hline Layer hens & & & & \\
\hline 1 & $58.10 \pm 0.637^{\mathrm{c}}$ & 50.03 & 63.45 & 6.01 \\
\hline 2 & $60.42 \pm 0.604^{\mathrm{bc}}$ & 54.46 & 66.89 & 5.48 \\
\hline 3 & $53.50 \pm 0.466^{\mathrm{d}}$ & 48.94 & 58.00 & 4.77 \\
\hline Broiler grandparent & & & & \\
\hline Female & $61.64 \pm 0.689^{b}$ & 54.93 & 68.17 & 6.12 \\
\hline Male & $69.21 \pm 0.919^{a}$ & 53.04 & 75.76 & 7.27 \\
\hline
\end{tabular}

$\overline{\mathrm{a}, \mathrm{b}, \mathrm{c}, \mathrm{d}}$ Means or percentages in a column with different superscripts differ significantly $(\mathrm{P}<0.05)$, ${ }^{1}$ SEM: Standard error means, ${ }^{2} \mathrm{CV}$ : Coefficient of Variance. 
Table 2. Number and percentage of embryos at each stage of development at oviposition time for the five strains.

\begin{tabular}{|c|c|c|c|c|c|c|}
\hline \multirow{2}{*}{ Strain } & \multirow{2}{*}{ Total } & \multicolumn{5}{|c|}{ Stage of blastoderm development ${ }^{1}$} \\
\hline & & EGK-VII & EGK-VIII & EGK-IX & EGK-X & EGK-XI \\
\hline \multicolumn{7}{|l|}{ Layer-1 } \\
\hline $\mathrm{n}$ & 22 & 0 & 0 & 3 & 18 & 1 \\
\hline$\%$ & 100 & 0.0 & 0.0 & 13.6 & $81.8^{a}$ & 4.6 \\
\hline \multicolumn{7}{|l|}{ Layer-2 } \\
\hline $\mathrm{n}$ & 24 & 0 & 0 & 3 & 21 & 0 \\
\hline$\%$ & 100 & 0.0 & 0.0 & 12.5 & $87.5^{\mathrm{a}}$ & 0.0 \\
\hline \multicolumn{7}{|l|}{ Layer-3 } \\
\hline $\mathrm{n}$ & 24 & 0 & 0 & 2 & 21 & 1 \\
\hline$\%$ & 100 & 0.0 & 0.0 & 8.3 & $87.5^{\mathrm{a}}$ & 4.2 \\
\hline \multicolumn{7}{|l|}{ Female } \\
\hline $\mathrm{n}$ & 16 & 0 & 0 & 4 & 10 & 2 \\
\hline$\%$ & 100 & 0.0 & 0.0 & 25.0 & $62.5^{\mathrm{ab}}$ & 12.5 \\
\hline \multicolumn{7}{|l|}{ Male } \\
\hline $\mathrm{n}$ & 19 & 2 & 3 & 6 & 8 & 0 \\
\hline$\%$ & 100 & 10.5 & 15.8 & 31.6 & $42.1^{\mathrm{b}}$ & 0.0 \\
\hline
\end{tabular}

${ }^{1}$ Based on Eyal Giladi and Kochav (1976) embryonic stage scale (EGK) within Roman numerals, a,b Percentages in a row with different superscripts differ significantly $(\mathrm{P}<0.05)$.

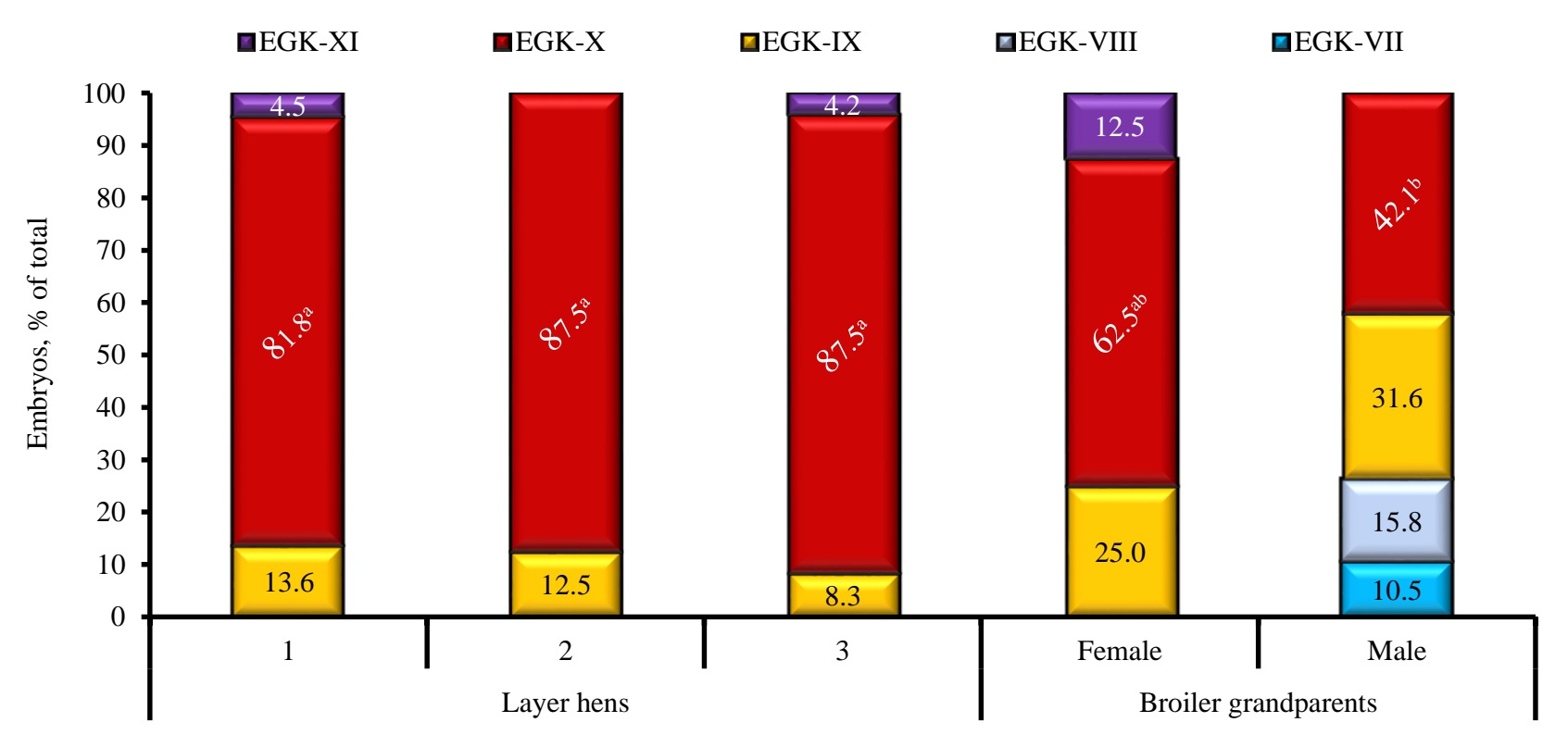

Flocks

Figure 1. The percentage of embryos at each stage of development at oviposition time for the five strains

\section{The Distribution of Blastoderm Developments}

The developments of the blastoderm were ranged from EGK-VII to EGK-XI in this study (Figure 1 and Table 2). In the studies of Fasenko et al. (1992a, b, 2001b), the most common stage of embryonic development in chickens at oviposition is stage " $\mathrm{X}$ " and they reported that embryos are mostly less developed when the developmental stage of the embryo at oviposition was below stage X (<EGK10). It has been hypothesized that embryos at developmental stages below EGK-X are sensitive to prolonged egg storage (Meir and Ar, 1998; Reijrink et al., 2009). The layer flocks had a-8.3-13.6\% percentage embryos which were less developed than stage EGK-IX. Most of embryos were at stage EGK-X in all layer flock eggs, and there were no significant differences among groups. Moreover, the two of three flocks had less than 5\% of embryos at stage EGK$\mathrm{XI}$ at oviposition time (>EGK-X). The female broiler breeder had $25.0 \%, 62.5 \%$, and $12.5 \%$ of embryos at stage EGK-IX, EGK-X, and EGK-XI, respectively. The stage EGK-X percentage was significantly lower in eggs which were collected from male broiler flock when compared to layer breeds $(\mathrm{P}<0.05)$. Moreover, only the male broiler breeder flock eggs had stage EGK-VIII and EGK-VII embryos in all flocks. However, there was no significant difference in percentage of the particular stage of the blastoderm development except stage EGK-X ( $>>0.05)$. Özlü et al. (2021b) found that $60.0 \%$ of the embryos from both broiler flocks were below the stage EGK-X, and $26.4 \%$ and $13.4 \%$ of the embryos were below the stage EGK-VIII of blastoderm development in the young and prime flock eggs at collection, respectively. In this study, all strain hens were at 36-wk old and there was no less than stage EGK-IX blastoderm developed embryos except the male broiler breeder eggs. 
Table 3. A comparison of the stage of blastoderm development from five strains eggs based on Eyal Giladi and Kochav (1976) embryonic stage scale (EGK) at oviposition.

\begin{tabular}{|c|c|c|c|}
\hline & & blastoderm devel & \\
\hline Strain & Mean $($ EGK $) \pm$ SEM $^{2}$ & $\operatorname{Median}^{3}(\mathrm{EGK})$ & $\% \mathrm{CV}^{4}$ \\
\hline Layer hens & & & \\
\hline 1 & $9.91 \pm 0.125^{\mathrm{a}}$ & $X^{a}$ & $4.30^{c}$ \\
\hline 2 & $9.88 \pm 0.119^{a}$ & $X^{a}$ & $3.42^{\mathrm{c}}$ \\
\hline 3 & $9.96 \pm 0.119^{\mathrm{a}}$ & $X^{a}$ & $3.60^{c}$ \\
\hline Broiler grandpare & & & \\
\hline Female & $9.88 \pm 0.146^{\mathrm{a}}$ & $X^{a}$ & $6.27^{\mathrm{b}}$ \\
\hline Male & $9.05 \pm 0.134^{\mathrm{b}}$ & $\mathrm{IX}^{\mathrm{b}}$ & $11.33^{\mathrm{a}}$ \\
\hline $\begin{array}{l}\mathrm{a,b,c} \text { Means or percentages } \\
\text { (EGK) within Roman nu }\end{array}$ & $\begin{array}{l}\text { ifferent superscripts differ } \\
\text { dard error means, }{ }^{3} \text { Median }\end{array}$ & $\begin{array}{l}.05),{ }^{1} \text { Based on Eyal } \\
\mathrm{H}=19.90, \mathrm{DF}=4, \mathrm{P}\end{array}$ & $\begin{array}{l}\text { 76) embryc } \\
\text { nt of Varia }\end{array}$ \\
\hline Strain & Pearson's Cc & Coefficient & $\overline{P \text { value }}$ \\
\hline Layer hens & & & \\
\hline$\sqrt{2}+a^{2}$ & & & 0.332 \\
\hline 2 & & & 0.930 \\
\hline 3 & & & 0.404 \\
\hline Broiler grandpare & & & \\
\hline Female & & & 0.509 \\
\hline Male & & & 0.461 \\
\hline
\end{tabular}

\section{The Coefficient of Variation for Blastoderm Developments}

Table 3 shows the coefficient of variation $(\mathrm{CV})$ for blastoderm development of the five breeder flock embryos. The male grandparent line eggs had a significantly higher variation in blastoderm development than those of female grandparent and layer hens embryos $(\mathrm{P}<0.05)$. Sellier et al. (2006) discovered that chicken and Muscovy duck blastoderms showed the least amount of developmental variation, but the Japanese quail blastoderm ranged from stage EGK-VI through stage EGK-XIV at oviposition time.

\section{The Average and Median of the Blastoderm Developments}

The averages of developmental stages ranged from EGK 9.05 to 9.96 in five flock embryos, and the male grandparent line significantly lower than other four lines $(\mathrm{P}<0.05)$. On the other hand, there was a significant difference in the coefficient of variance of the developmental stages of embryos, and the broiler grandparent lines had higher variation when compared to layer lines. In studies of Özlü et al. (2021 a, b), the average blastoderm development were determined stage EGK 8.779.71, EGK 9.00, and EGK 9.92 from young (27-28 wks), prime (40 wk), and old (58 wk) grandparent female lines. Besides, a study of the same research group reported that blastoderm stages of fresh eggs were EGK 8.9 and 10.1 for the young and old broiler flocks, respectively (Özlü et al., 2018). Dymond et al. (2013) stated that the average initial stage of commercial broiler parent stock eggs was stage EGK 10.5 at egg collection. Pokhrel et al. (2018) reported that the average developmental stage for fresh eggs of young and old flocks were EGK 10.9 and EGK 12.1, respectively. On the other hand, there was a significant difference in median of blastoderm development, and the male grandparent line embryos was significantly lower than other four genotypes $(\mathrm{P}<0.05)$.
Correlation Coefficient between Egg Weights with Stage of Blastoderm Development

Table 4 shows the correlation coefficients between egg weight and stage of blastoderm development. Although Pokhrel et al. (2017) reported that a positive correlation $(r=0.40)$ was observed between egg weight and stage of blastoderm development, in the present study for all flocks, there was no significant correlation between egg weight and stage of blastoderm development $(\mathrm{P}>0.05)$. Similarly, Arora and Matsumoto (1968) and Mather and Laughlin (1979) reported no significant relationship between egg weight and developmental stage after 2 days of incubation.

\section{Conclusion}

Genetic selection that has been carried out for several decades has led to significant progress in poultry production by improving various traits has caused different straints to have differing growth patterns. The paper discusses the cansequences of different strains from long term genetic selection on egg weight and blastoderm development at oviposition. It can be concluded that genetic selection affects not only production traits but also the developmental pattern of the embryos in the oviduct. Hence, it may be beneficial to adjust storage condition according to the line being used.

\section{Acknowledgements}

I gratefully acknowledge Dr. Serdar Kamanli (Poulty Research Institute, Ministry of Agriculture and Forest, Republic of Turkey) and Dr. Tolga Erkuş (Aviagen Ltd., Newbridge, Midlothian, United Kingdom) for supplied hatching eggs.

\section{References}

Arora KL, Matsumoto LH. 1968. Early embryogenesis of chicken eggs of different weights. Prooceedings of the Iowa Academy of Science, 75: 405-415. 
Badowski J, Bielinska H, Pakulska E, Wolc A. 2005. Relationships between some traits of hatching eggs and body weight of growing geese. In. Proceedings of the $17^{\text {th }}$ World's Poultry Science Association, Poznania, Pages 13-14.

Bakst M, Akuffo V, Nicholson D, French N. 2012. Comparison of blastoderm traits from 2 lines of broilers before and after egg storage and incubation. Poultry Science, 91:2645-2648.

Druyan S. 2010. The effects of genetic line (broilers vs. layers) on embryo development. Poultry Science, 89: 1457-1467.

Dupuy V, Nersessian B, Bakst MR. 2002. Embryonic development from first cleavage through seventy-two hours incubation in two strains of Pekin duck (Anas platyrhynchos). Poultry Science, 81: 860-868.

Durmuş İ, Türkoğlu M. 2007. Some production and egg quality traits in native white egg layer pure lines and their crossbred. Journal of Poultry Science, 7: 23-30.

Dymond J, Vinyard B, Nicholson AD, French NA, Bakst MR. 2013. Short periods of incubation during egg storage increase hatchability and chick quality in long-stored broiler eggs. Poultry Science, 92: 2977-2987.

Everaert N, Willemsen H, De Smit L, Witters A, De Baerdemaeker J, Decuypere E, Bruggeman V. 2008. Comparison of a modern broiler and layer strain during embryonic development and the hatching process. British Poultry Science, 49: 574-582.

Eyal Giladi H, Kochav S. 1976. From cleavage to primitive streak formation: a complementary normal table and a new look at the first stages of the development of the chick. I. General morphology. Developmental Biology, 49: 321-337.

Fasenko G, Hardin R, Robinson F, Wilson J. 1992a. Relationship of hen age and egg sequence position with fertility, hatchability, viability, and preincubation embryonic development in broiler breeders. Poultry Science, 71: 13741383.

Fasenko GM, Robinson FE, Hardin RT, Wilson JL. 1992b. Research note: variability in preincubation embryonic development in domestic fowl. 2. Effects of duration of egg storage period. Poultry Science, 71: 2129-2132.

Fasenko GM, Christensen VL, Wineland MJ, Petitte JN. 2001a. Examining the effects of prestorage incubation of turkey breeder eggs on embryonic development and hatchability of eggs stored for four or fourteen days. Poultry Science, 80: 132-138.

Fasenko GM, Robinson FE, Whelan AI, Kremeniuk KM, Walker JA. 2001b. Prestorage incubation of long-term stored broiler breeder eggs: 1. Effects on hatchability. Poultry Science, 80: 1406-1411.

Gucbilmez M, Özlü S, Shiranjang R, Elibol O, Brake J. 2013. Effects of preincubation heating of broiler hatching eggs during storage, flock age, and length of storage period on hatchability. Poultry Science, 92: 3310-3313.

Gupta S, Bakst M. 1993. Turkey embryo staging from cleavage through hypoblast formation. Journal of Morphology, 217: 313-325.

Hamburger V, Hamilton HL. 1992. A series of normal stages in the development of the chick embryo. Developmental Dynamics, 195: 231-272.

Ipek A, Sahan U. 2002. The effects of egg weight on the hatching characteristics of Ostrich eggs. Turkish Veterinary and Animal Science, 26: 723-728.

Jackson S, Diamond J. 1996. Metabolic and digestive responses to artificial selection in chickens. Evolution, 50: 1638-1650.

Koenen ME, Boonstra-Blom AG, Jeurissen SH. 2002. Immunological differences between layer-and broiler-type chickens. Veterinary immunology and immunopathology, 89: 47-56.

Łukaszewicz E, Lasoń M, Rosenberger J, Kowalczyk A, Bakst M. 2017. Goose embryonic development from oviposition through 16 hours of incubation. Poultry Science, 96:19341938 .
Mahagna M, Nir I. 1996. Comparative development of digestive organs, intestinal disaccharidases and some blood metabolites in broiler and layer-type chicks after hatching. British Poultry Science, 37: 359-371.

Mather CM, Laughlin KF. 1979. Storage of hatching eggs: The interaction between parental age and early embryonic development. British Poultry Science, 20: 595-604.

Meir M, Ar A. 1998. Pre-incubation warming as a means of lengthening storage time of fertile eggs. Proc. Proc. 10th European Poultry Conference, Israel. World's Poultry Science Association, Israel Branch, Jerusalem, Israel.

Nangsuay A, Molenaar R, Meijerhof R, van den Anker I, Heetkamp M, Kemp B, van den Brand H. 2015. Differences in egg nutrient availability, development, and nutrient metabolism of broiler and layer embryos. Poultry Science, 94: 415-423.

Ng'ambi JW, Thamaga MW, Norris D, Mabelebele M, Alabi OJ. 2013. Effects of egg weight on hatchability, chick hatchweight and subsequent productivity of indgenous Venda chickens in Polakwane, South Africa. South Africa Journal of Animal Science, 43: 69-74.

Özlü S, Elibol O, Brake J. 2018. Effect of storage temperature fluctuation on embryonic development and mortality, and hatchability of broiler hatching eggs1. Poultry Science, 97: 3878-3883.

Özlü S, Uçar A, Erkuş T, Nicholson AD, Elibol O. 2021a. Research Note: Effects of turning and short period of incubation during long-term egg storage on embryonic development and hatchability of eggs from young and old broiler grandparent flocks1. Poultry Science, 100:101026.

Özlü S, Uçar A, Erkuş T, Yasun S, Nicholson AD, Elibol O. 2021b. Effects of flock age, storage temperature, and short period of incubation during egg storage, on the albumen quality, embryonic development and hatchability of long stored eggs. British Poultry Science, 62: (In press) doi 10.1080/00071668.2021.1887454

Pokhrel N, Cohen EB, Genin O, Sela-Donenfeld D, Cinnamon Y. 2017. Celular and morphological characterization of blastoders from freshly laid broiler eggs. Poultry Science, 96: 4399-4408.

Pokhrel N, Cohen EB, Genin O, Ruzal M, Sela-Donenfeld D, Cinnamon Y. 2018. Effects of storage conditions on hatchability, embryonic survival and cytoarchitectural properties in broiler from young and old flocks. Poultry Science, 97: 1429-1440.

Reijrink I, Meijerhof R, Kemp B, Graat E, van den Brand H. 2009. Influence of prestorage incubation on embryonic development, hatchability, and chick quality. Poultry Science, 88: 2649-2660.

Sato M, Tachibana T, Furuse M. 2006. Heat production and lipid metabolism in broiler and layer chickens during embryonic development. Comparative Biochemistry and Physiology Part A: Molecular \& Integrative Physiology, 143: 382-388.

Sellier N, Brillard JP, Dupuy V, Bakst MR. 2006. Comparative staging of embryo development in chicken, turkey, duck, goose, guinea fowl, and Japanese quail assessed from five hours after fertilization through seventy-two hours of incubation. Journal of Applied Poultry Research, 15: 219-228.

Sözcü A, Ipek A. 2017. Effects of egg weight on chick and organ development, growth and slaughter traits in Pekin ducks. Journal of Biological \& Environmental Sciences, 11: 87-92.

van den Brand $H$, van de Kraats SJF, Sözcü A, Jöerissen R, Heetkamp MJW, van den Anker I, Ooms M, Kemp B. 2019. Both the rooster line and incubation temperature affect embryonic metabolism and hatchling quality in laying hen crossbreds. Poultry Science, 98: 2632-2640.

Weis J, Hrncar C, Pal G, Baranska B, Bujko J, Malikova L. 2011. Effect of the egg size on loses and hatchability of the Muscovy duck. Scientific Papers: Animal Sciences and Biotechnologies, 44: 354-356. 